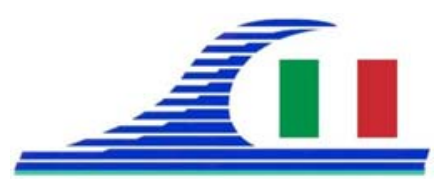

Conférence Méditerranéenne Côtière et Maritime EDITION 3, FERRARA, ITALIA (2015)

Coastal and Maritime Mediterranean Conference

Disponible en ligne - http://www.paralia.fr - Available online

\title{
Feasibility study of chemical stabilization of dredged marine sediment
}

\author{
Ana Paula FURLAN ${ }^{1,2}$, Andry Rico RAZAKAMANANTSOA ${ }^{2}$, \\ Yingjie LIANG ${ }^{2}$, Dimitri DENEELE ${ }^{2}$
}

1. Engineering School of Sao Carlos, University of Sao Paulo, EESC-USP, São Carlos, Brazil.afurlan@sc.usp.br

2 French Inst. of Science and Tech. for Transport, Development and Networks, IFSTTAR, Nantes, France. andry.razakamanantsoa@ifsttar.fr ; yingjie.liang@hotmail.com;dimitri.deneele@ifsttar.fr

\begin{abstract}
:
Chemical stabilization is one of techniques which can improve mechanical and hydraulic properties of dredged sediments. This paper presents an experimental study focused on different techniques of stabilization of dredged sediment from La Baule-Le Pouliguen (France). Dredged sediments are stabilized with lime, Portland cement and fly ash. Three mixes were produced and submitted to uniaxial compression strength (UCS), indirect tensile strength (ITS) and shear tests at different curing ages. In addition, suction and mercury porosimetry tests are performed to highlight the effect of binders on the microstructure of treated sediment. Results indicated sediment treated with lime plus cement and fly ash, is promising, despite the time necessary to obtain the threshold of UCS (1MPa); unfortunately, ITS reference value (0.25 MPa) was not obtained. But this mixture presented good performance of shear strength parameters, exhibiting higher increases in cohesion (c) and friction angle $(\phi)$ compared to the others mixes. In terms of porosimetry and suction results, it was observed that each type of binder acts differently, changing initial unimodal to bimodal porous distribution curves, and reducing suction in treated sediment due to macroporous occurrence and water retention for chemical reaction.
\end{abstract}

Keywords: Dredged sediment, Lime, Ordinary Portland Cement, Fly ash, Mechanical properties, Suction and porosimetry tests.

\section{Background}

Pavement sublayers tend to use not only conventional soils as construction materials but also marginal and alternative materials, since properly treated. In this way, it can be observed benefits such as reductions in (i) using of materials and non-renewable resources, (ii) exploitation of new deposits, (iii) the probable pollution that waste can generate and (iv) occupation of landfills (LIANG, 2012; LIMEIRA et al., 2010). The reduction of waste deposition site on land and dumping at the sea due to more rigorous environmental regulations led the French harbor authorities to study the reuse of fine 
Côtes méditerranéennes menacées :

Risques et défis dans le contexte du changement climatique

grained marine sediments from the solidification or stabilization of low or not polluted or no polluted fractions, for application in several infrastructures (SILITONGA, 2010). The present study promotes the use of a non-hazardous inert material, considered as a waste, in a material that can be used in pavement sub layers or in embankments. Among the recent studies, ZENTAR et al. (2008) demonstrate the possibility of use of $2 \%$ of quicklime and $7 \%$ of ordinary Portland cement to stabilize dredged sediment. Mechanical properties and potential pollution were monitored and it was concluded that this treated dredged sediment could be used as material on low traffic road pavement. LIANG (2012) and LIANG et al. (2014) studied dredged sediment from La Baule-Le Pouliguen treated with different types of binders: cement, lime and/or fibers, fly ash and have founded that lime and cement, cement and fly ash can increase UCS and ITS resistance in function of time. The previous study highlights the benefits of binders on the compressive strength of sediments. The present study is focused on binder effect on the direct shear behavior and pore size distribution of treated sediments.

\section{Materials and methods}

Geotechnical identification of Dredged Sediment (DS) was made according to the GTR recommendations (GTR, 2000). Results indicated that this material can be classified as silt clayey, with liquidity and plasticity limits equal to 55\% and 36\%, respectively, and plasticity index of $19 \%$. Dredged sediment presented organic matter content of approximately $11 \%$, carbonates content of $22 \%$ and a $\mathrm{pH}$ value of 8.5 . The lime named Proviacial $^{\circledR}$ ST was provided by LHOIST from Dugny-sur-Meuse in Lorraine. It contains at least $90 \%$ of $\mathrm{CaO}$ and at most $2 \%$ of $\mathrm{MgO}$ with a $\mathrm{pH}$ value of 8.5 . The Portland cement used was a CEM II/B-LL 32.5R CE CP2, some of the main characteristics are listed in Table 1 . The Sodeline ${ }^{\circledR}$ fly ash used, was manufactured in the Emile Huchet plant in Saint-Avold. Its chemical composition is given in Table 2.

Table 1. Portland cement characterization.

\begin{tabular}{ll}
\hline Clinker content & 65 to $79 \%$ \\
$(\mathrm{CaO})_{3}\left(\mathrm{Al}_{2} \mathrm{O}_{3}\right)$ & $7 \%$ \\
$(\mathrm{CaO})_{3}\left(\mathrm{SiO}_{2}\right)$ & $66 \%$ \\
$(\mathrm{CaO})_{2}\left(\mathrm{SiO}_{2}\right)$ & $10 \%$ \\
Main natural composite & Limestone with total organic material $\mathrm{C}<0,20 \%$ in mass \\
Compressive strength in short term & $32,5 \mathrm{MPa}$ \\
\hline
\end{tabular}

Table 2. Fly ash chemical compositions.

\begin{tabular}{lllllllllll}
\hline & $\mathrm{SiO}_{2}$ & $\mathrm{Fe}_{2} \mathrm{O}_{3}$ & $\mathrm{Al}_{2} \mathrm{O}_{3}$ & $\mathrm{MgO}$ & $\mathrm{MnO}_{2}$ & $\mathrm{CaO}_{\text {total }}$ & $\mathrm{CaO}_{\text {free }}$ & $\mathrm{Na}_{2} \mathrm{O}$ & $\mathrm{K}_{2} \mathrm{O}$ & $\mathrm{SO}_{3}$ \\
\hline \% Fly ash & 47.36 & 7.09 & 21.63 & 3.32 & 0.62 & 8.52 & 0.90 & 0.46 & 4.35 & 4.02 \\
\hline
\end{tabular}


Sediment-binder mixtures were prepared for different binder contents stated in previous study (LIANG et al., 2014) taking into account economic and environmental approaches. Thus, mixtures are made with lime, Portland cement and fly ash, with contents of 2, 7 and 9\%, respectively. Specimens are compacted in regard of optimum Proctor characteristics of treated specimen. Mechanical tests performed were uniaxial compression strength (UCS), indirect tensile strength (ITS) and direct shear tests. Furthermore, suction tests (WP4 - Decagon Devices) and Mercury Intrusion Porosimetry were run to observe some particular behavior due to cement hydration and pozzolanic action.

\section{Results and discussion}

Table 3 gathers Proctor parameters of untreated dredged sediment and of mixes proposed. Changes due to the addition of binders are highlighted. Regarding all the mixtures the addition of lime and fly ash increased optimum water content and decreased the maximum dry density and, this effect is more pronounced when lime is added. It is noted that Portland cement appears to increase maximum dry densities as compared to the mixtures containing lime.

Table 3. Proctor parameters.

\begin{tabular}{llll}
\hline Mixtures & Symbol & $W_{\text {opm }}(\%)$ & $\gamma_{d}\left(\mathrm{~g} / \mathrm{cm}^{3}\right)$ \\
\hline Dredge sediment: without treatment & DS & 27.8 & 1.48 \\
Dredge sediment $+2 \%$ Lime + 9\% Fly Ash & DS+lime+fly ash & 32.0 & 1.37 \\
Dredge sediment + 7\% Cement + 9\% Fly Ash & DS+cement+fly ash & 30.3 & 1.41 \\
Dredge sediment + 2\% Lime + 7\% Cement + 9\% Fly Ash & DS+lime+cement+fly ash & 31.6 & 1.37 \\
\hline
\end{tabular}
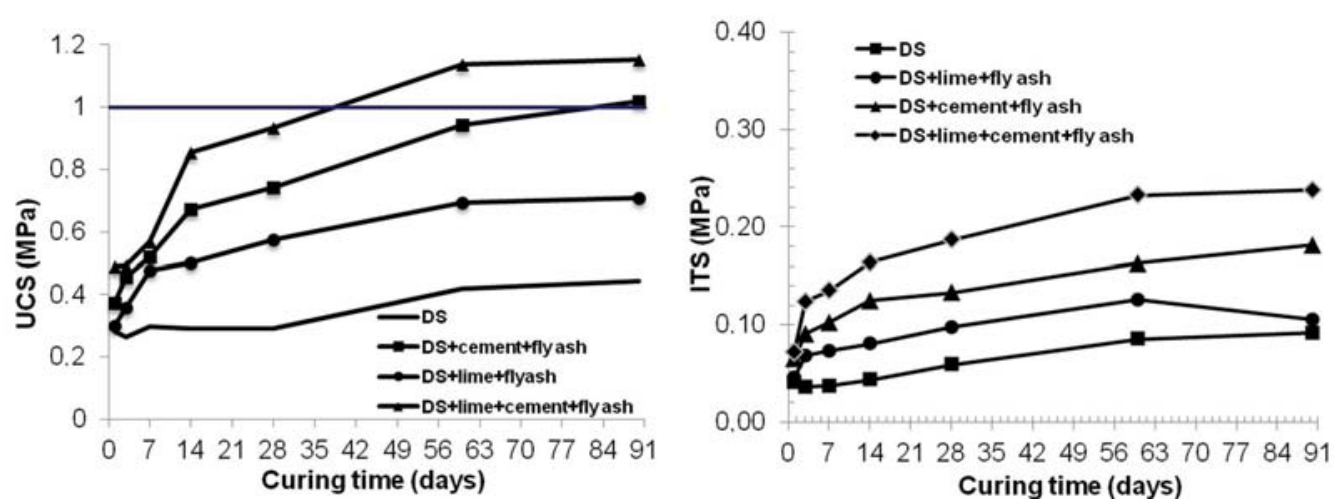

Figure 1. UCS and ITS of tested mixtures.

Figure 1 shows UCS and TS results in function of curing period. On the figure, the reference threshold is drawn as recommended by French standard and represented by UCS equals to $1 \mathrm{MPa}$. It can be noted that: (i) for UCS values: only DS+lime+cement+fly ash and DS+cement+fly ash reach the threshold, and (ii) for ITS 
Côtes méditerranéennes menacées :

Risques et défis dans le contexte du changement climatique

values: despite the weak values, it can be observed that DS+lime+cement+fly ash and DS+cement+fly ash mixes have higher values.

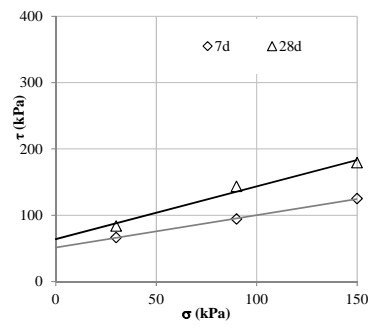

$D S$

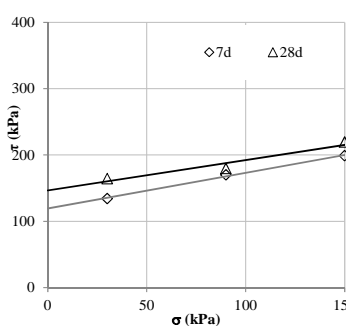

DS +lime +fly ash

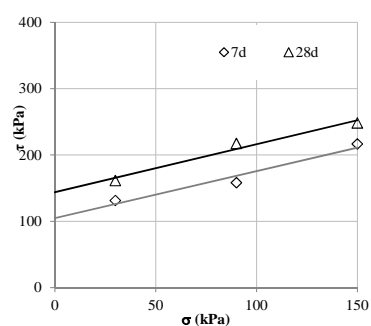

$D S+$ cement + fly ash

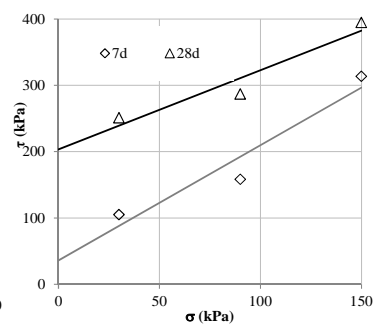

DS +lime+cement + fly ash

Figure 2. Strength envelopesof mixes with dredged sediment.

Figure 2 presents the failure envelopes from direct shear data. Specimen were prepared to get the optimum moisture content, corresponding to each mixture and compacted in a cylindric mould to obtain the optimum dry density before being packed and conserved in polyethylene films. Specimens are conserved in air conditioned laboratory in order to keep the hydric equilibrium during the period of cure: 7 days and 28 days. Before the direct shear test, specimen were placed inside the shear box and consolidated for 12 hours. The shearing speeds were determined and direct shear test were performed under 4 normal stresses.

Usually, after a curing period there was an increment of cohesion and friction angle $\varphi$ also increased slightly. Figure 2 highlights how changes shear strength in function of different types of binders which were added. Considering DS sample, it can be noted that this condition provided the lowest shear parameter values and the lowest increments in cohesion vs curing time. DS sample results show that the curing time increase the friction angle but has low influence of the gain of cohesion. Increments in strength parameters were more important in treated materials than in DS.

Fly ash addition to the mixture with lime and cement resulted in better performance. But 28 days-curing period is needed to get an increase of the cohesion. Other significant observation is that the $\varphi$ changes, it seems to be a particular contribution of the combination among lime+cement+fly ash. To understand the binder addition effect on pore size distribution of dredged sediment, mercury intrusion porosimetry tests were performed and results are presented in Figure 3. Figure 3 shows pore size distribution curves related to mercury volume for 7-days curing time. The 2 main peaks concern the main pore size diameter of the specimen. Notice that for untreated sediment the pore distribution exhibits two defined slight peaks of low occurrence intensity (less than 0.1 $\mu \mathrm{m})$ as compared with the other curves. Regarding treated mixtures, there were changes in peak size values and in its intensity. Specimen behaviour depends on the type of binder used, but, the reduction of macro pore size occurs for all specimen excepted DS. And the slight increase of micro pore might be attributed to the fine-grained gradation 
with the fly ash, which promotes the decrease of macropore, combined with the well known ability of lime to generate micro pore. Cement adding seems to reduce only the macro pore by its cementation ability.

To clarify different binder effects on mechanical behavior, results of suction and porosimetry tests are presented in Table 4 . These results are presented in mean values.
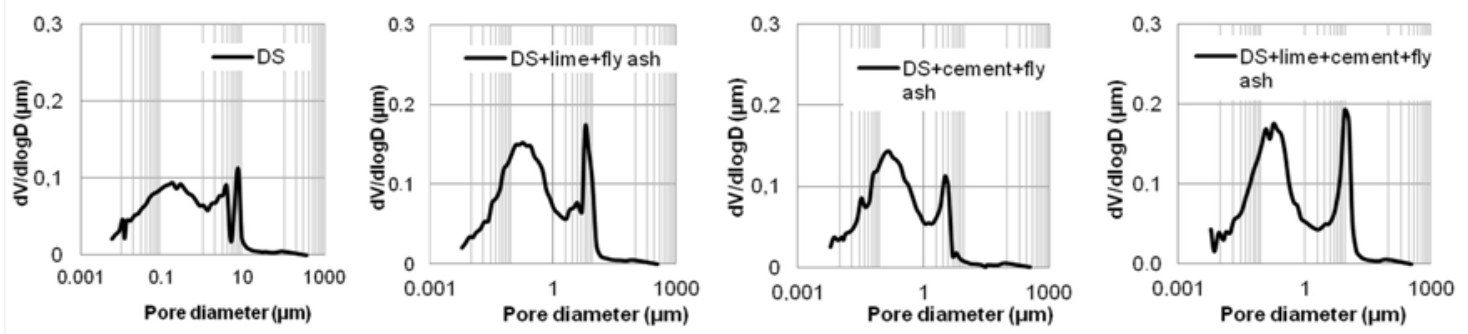

Figure 3. Pore diameter curves.

Table 4. Suction and pore diameter values.

\begin{tabular}{llllllllllllll}
\hline & \multicolumn{3}{c}{ Proctor } & \multicolumn{3}{c}{$\begin{array}{l}\text { Tested } \\
\text { specimen }\end{array}$} & \multicolumn{9}{c}{$\omega\left(105^{\circ}\right)$} & $\omega\left(50^{\circ} \mathrm{C}\right)$ & Suction $(\mathrm{kPa})$ & Pore size (mm) \\
\cline { 2 - 13 } Note: $d=$ days & $\omega$ & $\rho_{d}$ & $\omega$ & $\rho_{d}$ & $7 d$ & $28 d$ & $7 d$ & $28 d$ & $7 d$ & $28 d$ & Micro & Macro \\
\hline DS & 27.8 & 1.48 & 27.1 & 1.5 & 27.1 & 26.7 & 25.1 & 25.0 & 14205 & 14440 & 0.183 & 7.2 \\
DS+lime+fly ash & 32.0 & 1.37 & 30.7 & 1.39 & 30.4 & 30.5 & 28.5 & 28.9 & 10460 & 10790 & 0.227 & 6.0 \\
DS+cement+fly ash & 30.3 & 1.41 & 28.0 & 1.45 & 27.6 & 27.1 & 24.5 & 25.7 & 11660 & 11300 & 0.151 & 3.2 \\
DS+lime+cement+fly ash & 31.6 & 1.37 & 31.0 & 1.39 & 28.5 & 27.7 & 25.9 & 25.9 & 11490 & 10975 & 0.183 & 9.1 \\
\hline
\end{tabular}

The highest suction value was presented by DS and binder adding tends to decrease the suction value. A suction value depicts that:

(a) dredged sediment showed an increasing in suction values of $2 \%$ as a result of water content reduction in 2\%: it suggests that the effect of suction on strength parameter can be significant in cases where desiccation occurs; this effect is reversible by wetting;

(b) cement+lime+fly ash and cement-fly ash mixtures reduced in $20 \%$ the DS suction and after curing time suction values decreased about 3\%. Some explanations can be proposed: the water distribution inside the compacted specimen is different to DS. The important grain contacts inside DS specimen are reduced by the presence of binder. This phenomenon tends to decrease the amount of tensile strength generated by water menisci between particles and can cause a decrease of the suction value. Porosimetry results helps to clarify which fly ash fine-grained particles contributed to makes mixtures finer and increasing slightly suction values. 
Côtes méditerranéennes menacées :

Risques et défis dans le contexte du changement climatique

\section{Conclusions}

An alternative study about chemical stabilization of dredged sediment was presented, considering mixes composed by Dredged Sediment (DS) treated with lime, ordinary Portland cement and fly ash. Results indicated that: Mixture with sediment+lime+ciment+fly ash can be considered promising, despite the time necessary to obtain the GTR references. It is important to remember that this experimental solution did not consider physical stabilization, thus no one type of gradation correction was applied. Suction tests indicated that dredged sediment has high water pressure and after stabilization with binders, suction is decreasing. In spite of suction reduction, all of strength values increased after curing process, indicating that strength increments can be related to chemical reaction. Porosimetry results exhibited that macropores are reduced in terms of size and intensities and cause an intimate contact between particles. The first result is the increase of the saturation degree which is responsible of the decrease of the suction values.

\section{Acknowledgements}

Special thanks to GERS-GMG-IFSTTAR from Nantes, France, for making available laboratory infrastructure and to Jean Pierre David for his valuable technical support.

\section{References}

GTR (2000). Guide des Terrassements Routiers, réalisation de remblais et des couches de formes, fascicules I et II. GTR SETRA-LCPC $2^{\text {ème }}$ édition, juillet 2000, 211 p.

LIANG Y. (2012). Co-valorisation de sédiment et de sols fins par apport de liants et de fibres. Thèse de doctorat, Université de Caen, 194 p.

LIANG. Y, LEVACHER D., DENEELE D., RAZAKAMANANTSOA A. (2014). Effets des cendres volantes sur le comportement mécanique de sédiments méditerranéens traités à base de ciment et de chaux. JNGCGC, Dunkerque. France, pp 1017-1026. http://dx.doi.org/10.5150/jngcgc.2014.112

LIMEIRA J., AGULLO L., ETXEBERRIA M., (2010). Dredged marine sand in concrete: An experimental section of a harbor pavement. Construction and Building Materials, Vol. 24(6), pp 863-870. http://dx.doi.org/10.1016/j.conbuildmat.2009.12.011

SILITONGA E. (2010). Valorisation des sédiments marins contaminés par solidification / stabilisation à base de liants hydrauliques et de fumée de silice. Thèse de Doctorat, Université de Caen, 227 p.

ZENTAR R., DUBOIS V., ABRIAK N.E. (2008). Mechanical behaviour and environmental impacts of a test road built with marine dredged sediments. Resources, Conservation and Recycling, Vol. 52(6), pp 947-954. http://dx.doi.org/10.1016/j.resconrec.2008.02.002 